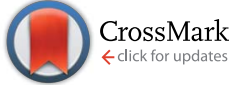

Cite this: RSC Adv., 2017, 7, 7046
Received 7th December 2016

Accepted 16th December 2016

DOI: $10.1039 / c 6 r a 27857 d$

www.rsc.org/advances

\section{Low-temperature fabrication of lithium aluminum oxide phosphate solid electrolyte thin films from aqueous precursors $\dagger$}

\begin{abstract}
D. R. Clayton, D. Lepage, P. N. Plassmeyer, C. J. Page and M. C. Lonergan*
Low-temperature routes to solid electrolytes are important for construction of solid-state batteries, electrochromic devices, electrolyte-gated transistors, high-energy capacitors and sensors. Here we report an environmentally friendly aqueous solution route to amorphous thin films of the solid electrolyte lithium aluminum oxide phosphate (LiAIPO). This route allows production of high quality films at very low temperatures $\left(275^{\circ} \mathrm{C}\right), 600^{\circ} \mathrm{C}$ lower than traditional melt quenching routes to LiAlPO. Films of thicknesses ranging from 20-150 nm produced by this route are extremely smooth and fully dense, with temperature dependent conductivities similar to those reported for samples made by melt quenching techniques. The average room temperature conductivity of LiAlPO films was measured to be $\sigma_{\mathrm{DC}}=2.6 \times 10^{-8} \mathrm{~S} \mathrm{~cm}^{-1}$. Film evolution was monitored by TGA-DSC and FTIR, and resulting films were characterized using FTIR, XPS, SEM, and XRD. These techniques indicate that water and nitrate removal is complete by $250{ }^{\circ} \mathrm{C}$, and the films remain amorphous to $400{ }^{\circ} \mathrm{C}$. The approach developed demonstrates a simple, inexpensive and environmentally benign deposition route for the fabrication of inorganic solid electrolyte thin films, using LiAlPO as a model system.
\end{abstract}

\section{Introduction}

Thin films of inorganic solid electrolytes (ISEs) have received considerable interest in recent years for use in a variety of devices including rechargeable batteries, electrochromics, electrolytegated transistors, high-energy capacitors, sensors, and other electrochemical devices. ${ }^{1-9}$ The reported advantages of ISEs include increased safety, reliability, and thermal stability.,2,10,11 Thin films are needed for compact device structures and to improve electrolyte conductance. Methods for the fabrication of thin film ISEs, however, are primarily limited to expensive vacuum deposition techniques and/or require high temperature annealing, which is energy intensive and hinders integration with materials of low thermal stability.

We demonstrate herein the use of prompt inorganic condensation (PIC) as a low-temperature, solution-cast route to high quality thin films of the solid electrolyte $\mathrm{Li}_{5} \mathrm{Al}_{2} \mathrm{O}\left(\mathrm{PO}_{4}\right)_{3}$ (LiAlPO) using only aqueous precursors. PIC is a powerful approach that has been developed for the synthesis of oxide thin films. ${ }^{12}$ It is based on the use of aqueous precursors consisting of simple inorganic salts or clusters that concentrate during spin coating, and rapidly condense to form metal oxide networks with

Department of Chemistry and Biochemistry, University of Oregon, Eugene, OR 97403, USA.E-mail: lonergan@uoregon.edu

$\dagger$ Electronic supplementary information (ESI) available: XPS survey scan, films thickness as a function of precursor concentration, and XPS atomic ratios. See DOI: $10.1039 / \mathrm{c} 6 \mathrm{ra} 27857 \mathrm{~d}$ low-temperature annealing, with further dehydration and possibly decomposition of small inorganic counterions at moderately elevated temperatures. To date, PIC has been primarily used in the synthesis of thin-film oxide dielectrics, semiconductors, and nanolaminates of these compounds. ${ }^{13-18}$ This is the first demonstration of its use for the synthesis of thin film ISEs.

Bulk LiAlPO has been previously synthesized by classic melt quenching techniques requiring temperatures in excess of $750{ }^{\circ} \mathrm{C} .{ }^{19}$ To date, thin films of this material have not been reported. By using PIC, we are able to greatly reduce the processing temperatures, and prepare this material readily in thinfilm form. Previously, PIC has been used to prepare aluminum oxide phosphate thin films with $\mathrm{P}: \mathrm{Al}$ ratios ranging from 0.5 to 1.0. ${ }^{14}$ The extension of this work into the synthesis of lithium alumino phosphate glasses with a higher $\mathrm{P}: \mathrm{Al}$ ratio $(1.5: 1)$ and added lithium demonstrates the flexibility of the PIC method to produce amorphous films over a range of stoichiometries.

Although LiAlPO has not been previously synthesized by a solution-based approach, other ISEs have. However, most currently available approaches that produce quality ISE thin films employ environmentally harsh solvents, such as hydrazine, or rely on organic ligands and/or solvents. ${ }^{20,21}$ For example, sol-gel synthesis typically utilizes metal alkoxide or citrate precursors and organic solvents. The removal of these solvents and ligands result in undesirable film characteristics including cracking and void formation. ${ }^{22,23}$ Although PIC requires the 
liberation of water and possibly counterion decomposition products, cracking and surface roughness are not commonly observed in films prepared by this method. ${ }^{\mathbf{1 4 , 1 7}}$ Further, in many cases the removal of water and counterions can be achieved at low temperatures, as in the present study. ${ }^{\mathbf{1 4 , 1 7}}$ Moreover, the use of water as a solvent has obvious benefits in terms of sustainability and hazard reduction. Previous reports of thin-film ISEs from aqueous solutions are exceptionally limited. Most closely related to the work herein is that of van den Ham et al., who reported an aqueous precursor route to thin films of an amorphous lithium lanthanum titanate perovskite ISE. ${ }^{\mathbf{2 4}}$ These authors used an aqueous citrate-peroxo-Ti(Iv) precursor, which required annealing temperatures of $500{ }^{\circ} \mathrm{C}$ for complete decomposition and elimination of citrate. Here we demonstrate that PIC using nitrate and phosphate precursors can be used to synthesize dehydrated, smooth, uniform LiAlPO films at temperatures as low as $275^{\circ} \mathrm{C}$.

\section{Experimental}

\section{Precursor synthesis}

The LiAlPO precursor solution was prepared with the addition of $50 \mathrm{mmol} \mathrm{Al}(\mathrm{OH})_{3} \cdot x \mathrm{H}_{2} \mathrm{O}$ (Alfa Aesar) to $50 \mathrm{~mL}$ of $18 \mathrm{M} \Omega \mathrm{H}_{2} \mathrm{O}$. The level of hydration in $\mathrm{Al}(\mathrm{OH})_{3} \cdot x \mathrm{H}_{2} \mathrm{O}$ was determined gravimetrically through thermal conversion to the oxide $\left(\mathrm{Al}_{2} \mathrm{O}_{3}\right)$. Complete dissolution was achieved following the addition of $100 \mathrm{mmol}$ of $\mathrm{HNO}_{3}$ (EMD Chemicals $70 \% \mathrm{w} / \mathrm{w}$ ) with one hour of stirring at $80{ }^{\circ} \mathrm{C}$. To the clear solution $75 \mathrm{mmol}$ of $\mathrm{H}_{3} \mathrm{PO}_{4}$ (EMD Chemicals $85 \% \mathrm{w} / \mathrm{w}$ ) was slowly added. The solution was stirred overnight with heating $\left(80^{\circ} \mathrm{C}\right)$. The solution was allowed to cool to room temperature and $137.5 \mathrm{mmol}$ of solid $\mathrm{LiNO}_{3}$ (Alfa Aesar) was added. The mixture was stirred at room temperature until complete dissolution of the $\mathrm{LiNO}_{3}$ ( $\sim 10$ minutes). The solution was diluted with $18 \mathrm{M} \Omega \mathrm{H}_{2} \mathrm{O}$ to achieve a $0.4 \mathrm{M}$ concentration with respect to $\mathrm{Al}$. The $\mathrm{P}: \mathrm{Al}: \mathrm{Li}$ ratio was $1.5: 1: 2.5$ for all precursor solutions. This concentration of precursor solution was used for all characterization with the exception of FTIR analysis for which films were prepared with solutions of $0.7 \mathrm{M}$ with respect to $\mathrm{Al}$.

\section{Film deposition and device fabrication}

All of the films were prepared by solution deposition of a single layer via spin-processing. Boron doped Si substrates (0.008$0.020 \Omega \mathrm{cm}$ ) were sonicated in a five percent Contrad 70 solution for $60 \mathrm{~min}$ at $50{ }^{\circ} \mathrm{C}$. Substrates were then treated by plasma cleaning to produce a hydrophilic surface $\left(120 \mathrm{~s} \mathrm{O}_{2} / \mathrm{N}_{2}\right.$ plasma etch using a Plasma Etch, Inc. PE-50 Benchtop Plasma Cleaner set to maximum power). The precursor solution was filtered $(2 \times)$ through a $0.45 \mu \mathrm{m}$ Teflon filter. Substrates were flooded with the filtered LiAlPO precursor solution via syringe and spun at $3000 \mathrm{rpm}$ for $30 \mathrm{~s}$. An immediate hot plate cure at $275^{\circ} \mathrm{C}$ took place for one minute. A final anneal at either 275 or $400{ }^{\circ} \mathrm{C}$ was then carried out for one hour. An array of circular $\left(0.011 \mathrm{~cm}^{2}\right) \mathrm{Al}$ top contacts were thermally evaporated onto the LiAlPO surface via shadow mask. An Al plate adhered by silver print to the silicon wafer was used for a back contact.

\section{Characterization}

Weight loss and thermal stability of evaporated LiAlPO precursor powders were analysed using a TA Instruments Thermogravimetric Analyzer (TGA Q500). Further thermal characterization was conducted using a TA Instruments Differential Scanning Calorimeter (DSC-2920). For these measurements, the precursor solution was evaporated at $100{ }^{\circ} \mathrm{C}$ for one hour yielding $10-30 \mathrm{mg}$ powder samples. A heating rate of $2-10{ }^{\circ} \mathrm{C} \mathrm{min}^{-1}$ from room temperature to $600{ }^{\circ} \mathrm{C}$ was completed for TGA analysis. DSC measurements were completed using a heating rate of $10^{\circ} \mathrm{C} \mathrm{min}{ }^{-1}$ from room temperature to $460{ }^{\circ} \mathrm{C}$.

$\mathrm{X}$-ray reflectivity and diffraction measurements on film samples were collected on a Bruker AXS D8 Discover diffractometer with $\mathrm{Cu} \mathrm{K} \alpha$ radiation to determine the total film thickness and confirm amorphous character. The chemical characteristics of the LiAlPO films were investigated by transmission Fourier transform infrared spectroscopy (Thermo Scientific Nicolet 6700 FT-IR Spectrometer) and X-ray photoelectron spectroscopy (Thermo Scientific ESCALAB 250 X-ray Photoelectron Spectrometer). All binding energies were referenced to the $\mathrm{C} 1 \mathrm{~s}$ peak of carbon at $284.8 \mathrm{eV}$. NIST and LaSurface XPS databases were used for binding energy assignments. Film morphology and thickness were characterized using a ZEISS Ultra-55 Scanning Electron Microscope. Impedance spectroscopy measurements were performed using a Solartron 1260 Impedance Analyzer and 1296 Dielectric Interface over the frequency range $10 \mathrm{mHz}$ to $1 \mathrm{MHz}$. Temperature control was achieved using a Sun Electronic Systems Environmental Chamber (Model EC1X). The apparent relative permittivity $\varepsilon_{\text {app }}=$ $\varepsilon_{\text {app }}^{\prime}-\mathrm{i} \varepsilon^{\prime \prime}{ }_{\text {app }}$ and conductivity $\sigma_{\text {app }}=\sigma_{\text {app }}^{\prime}+\mathrm{i} \sigma^{\prime \prime}{ }_{\text {app }}$ were calculated from the raw complex impedance $Z$ in the standard manner: $\varepsilon_{\text {app }}$ $=\sigma_{\mathrm{app}} / \mathrm{i} \omega \varepsilon_{0}=L / \mathrm{i} \omega A Z \varepsilon_{0}$ where $\varepsilon_{0}$ is the vacuum permittivity. The dielectric loss tangent $\tan \delta=\varepsilon^{\prime \prime}{ }_{\text {app }} / \varepsilon^{\prime}$ app $=\tan (\theta+\pi / 2)$, where $\theta$ is the measured phase angle, was also calculated.

\section{Results and discussion}

The PIC synthesis of LiAlPO thin films reported herein involves spin casting an aqueous solution of salts and acids with appropriate stoichiometry followed by mild heating to produce an amorphous oxide film according to the following idealized chemical reaction:

$$
\begin{aligned}
& 2 \mathrm{Al}(\mathrm{OH})_{3}(\mathrm{aq})+4 \mathrm{HNO}_{3}(\mathrm{aq})+5 \mathrm{LiNO}_{3}(\mathrm{aq})+3 \mathrm{H}_{3} \mathrm{PO}_{4}(\mathrm{aq}) \underset{(1)}{\rightarrow} \\
& \mathrm{Li}_{5} \mathrm{Al}_{2} \mathrm{O}\left(\mathrm{PO}_{4}\right)_{3}(\mathrm{~s})+9 \mathrm{HNO}_{3}+5 \mathrm{H}_{2} \mathrm{O} .
\end{aligned}
$$

Note that nitric acid is added to solubilize the $\mathrm{Al}(\mathrm{OH})_{3}$. Ideally, the nitric acid product is liberated as its azeotrope with water at relatively low temperature (boiling point $121^{\circ} \mathrm{C}$ ), but some nitrate incorporation into the LiAlPO product is also likely to occur. To explore this further, thermal analysis was first performed on bulk powders of dried precursor solution. Specifically, a solution containing $\mathrm{Al}(\mathrm{OH})_{3}$ (solubilized with $\mathrm{HNO}_{3}$ ), $\mathrm{H}_{3} \mathrm{PO}_{4}$, and $\mathrm{LiNO}_{3}$ in the molar ratios of eqn (1) was evaporated to near complete dryness at $100{ }^{\circ} \mathrm{C}$. Fig. 1 shows TGA-DSC analysis of the resulting powder. Beginning near $100{ }^{\circ} \mathrm{C}$, there is an initial mass loss of nearly $20 \%$ accompanied by a broad endotherm. This is assigned to the continued 


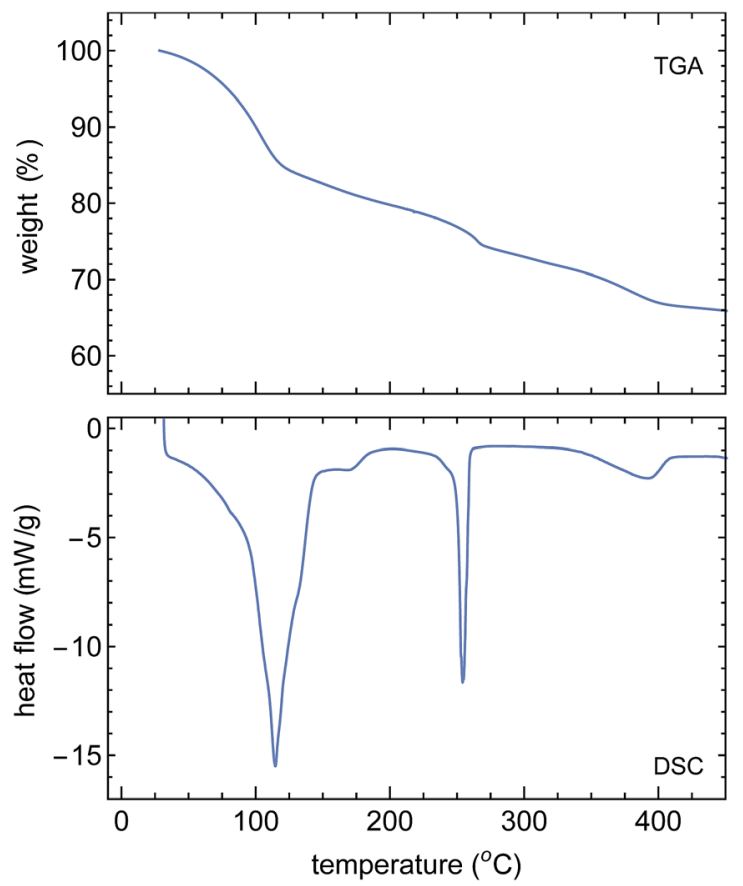

Fig. 1 TGA and DSC curves of a LiAIPO precursor powder from 20 to $450{ }^{\circ} \mathrm{C}$.

dehydration of the powder and the elimination of nitrate from the film as the $\mathrm{H}_{2} \mathrm{O} / \mathrm{HNO}_{3}$ azeotrope. Above $120^{\circ} \mathrm{C}$ in the tail of the endotherm, mass loss continues at a relatively constant and more gradual rate, with the exception of two small features in the TGA. One corresponds with a sharp endotherm at $255{ }^{\circ} \mathrm{C}$, which coincides with the melting temperature of $\mathrm{LiNO}_{3}$. The second has an onset of $340{ }^{\circ} \mathrm{C}$, and we assign it to the decomposition of residual nitrates in the film. This assignment is supported by IR data on thin films discussed below and indicates that nitrates are not completely removed via the $\mathrm{H}_{2} \mathrm{O}$ / $\mathrm{HNO}_{3}$ azeotrope evaporation, at least in bulk powders. For comparison, the decomposition of simple nitrate salts of the main group elements can occur over a wide range of temperatures from as low as $170{ }^{\circ} \mathrm{C}$ for pure aluminum nitrate to $640{ }^{\circ} \mathrm{C}$ for pure lithium nitrate. ${ }^{25}$

The thermal analysis data on bulk powders motivated us to study LiAlPO thin film formation at temperatures of $275^{\circ} \mathrm{C}$ and $400{ }^{\circ} \mathrm{C}$. Although dehydration, condensation, and nitrate decomposition are likely different in spin-coated thin films relative to bulk powders, we expected that these temperatures would be sufficiently high to result in near complete dehydration as well as to enable comparison of the effects of residual nitrate in the film.

Thin films were made by first spin casting a precursor solution of the same composition used in the thermal analysis experiments onto cleaned silicon substrates, followed by rapid annealing at either $275{ }^{\circ} \mathrm{C}$ or $400{ }^{\circ} \mathrm{C}$ on a hot plate.

Films annealed at both temperatures were determined to be amorphous by XRD. This is consistent with the crystallization temperature for glassy LiAlPO of greater than $500{ }^{\circ} \mathrm{C}$ reported by Reddy et $a .^{26}$ Amorphous films are desirable to maintain transparency and to prevent localized current pathways associated with grain boundaries in crystalline materials. The formation of amorphous films illustrates how PIC is distinctly different from the simple co-precipitation of aqueous salts. Slow heating to $275{ }^{\circ} \mathrm{C}$ of the dried LiAlPO precursor solution produced powders with diffraction peaks indicative of tridymite and cristobalite $\mathrm{AlPO}_{4} \cdot{ }^{14}$ The resistance to crystallization in the PIC method is attributed to prompt dehydration and condensation to form an initial glass network during spin coating and rapid annealing.

To better understand the formation of LiAlPO thin films using PIC, FTIR spectra were collected as a function of annealing temperature (Fig. 2). Several peaks were monitored to confirm formation of the alumino-phosphate network and track changes in composition. Remarkably, absorption near 3600 $\mathrm{cm}^{-1}$ and $1640 \mathrm{~cm}^{-1}$ attributed to the presence of water were not observed, even after annealing at $275{ }^{\circ} \mathrm{C}$ for only one minute. This is in contrast to thin films of a different $\mathrm{P}: \mathrm{Al}$ ratio, $\mathrm{Al}_{2} \mathrm{O}_{3-3 x}\left(\mathrm{PO}_{4}\right)_{2 x}$ (AlPO) produced via PIC in which films of similar thickness show detectable water absorptions up to $600{ }^{\circ} \mathrm{C}^{.14}$ Peaks in the $1200-1700 \mathrm{~cm}^{-1}$ are assigned to nitrate deformation vibrations. They were observed in the $275{ }^{\circ} \mathrm{C}$ annealed sample but not in the $400{ }^{\circ} \mathrm{C}$ sample indicating near complete nitrate decomposition had occurred in the latter. This supports the assignment above of the DSC endotherm to nitrate decomposition at $340{ }^{\circ} \mathrm{C}$. The strong peak located at $1120 \mathrm{~cm}^{-1}$ is attributed to the phosphate absorption band and is present at both annealing temperatures. Peaks between $400-950 \mathrm{~cm}^{-1}$ are associated with both $\mathrm{Al}-\mathrm{O}$ and $\mathrm{P}-\mathrm{O}$ vibrations. ${ }^{14,27}$

Thin-film chemical composition was further analysed via XPS. A survey scan revealed the presence of $\mathrm{Li}, \mathrm{Al}, \mathrm{P}, \mathrm{C}, \mathrm{N}$, and $\mathrm{O}$ (Fig. S1†). The observed ratios of $\mathrm{Li}: \mathrm{Al}: \mathrm{P}: \mathrm{O}$ match that of the precursor solution in samples processed at $275{ }^{\circ} \mathrm{C}$ and are presented in Table S1. $\dagger$ It is noted that adventitious carbon was observed in all of the films due to air exposure with the $\mathrm{C} 1 \mathrm{~s}$ peak at $284.8 \mathrm{eV}$ serving as a charge correction reference.

The relative oxygen content did not change over a range of annealing conditions consistent with near complete dehydration of the film by $275{ }^{\circ} \mathrm{C}$. As shown Fig. 3 , the $\mathrm{O} 1 \mathrm{~s}$ peak shape was somewhat different between the $275^{\circ} \mathrm{C}$ and $400{ }^{\circ} \mathrm{C}$ samples. The shape at $275{ }^{\circ} \mathrm{C}$ was best fit with a convolution of peaks

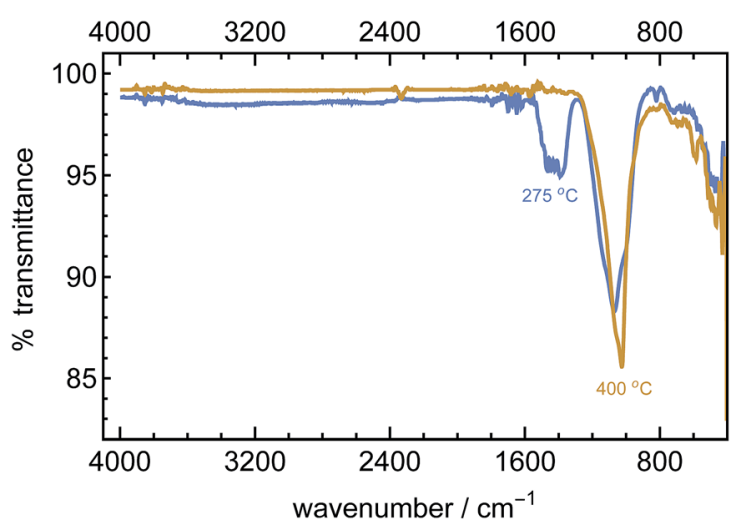

Fig. 2 FTIR spectra of $120 \mathrm{~nm}$ LiAlPO films annealed at $275^{\circ} \mathrm{C}$ (blue) and $400{ }^{\circ} \mathrm{C}$ (orange) for one hour. 

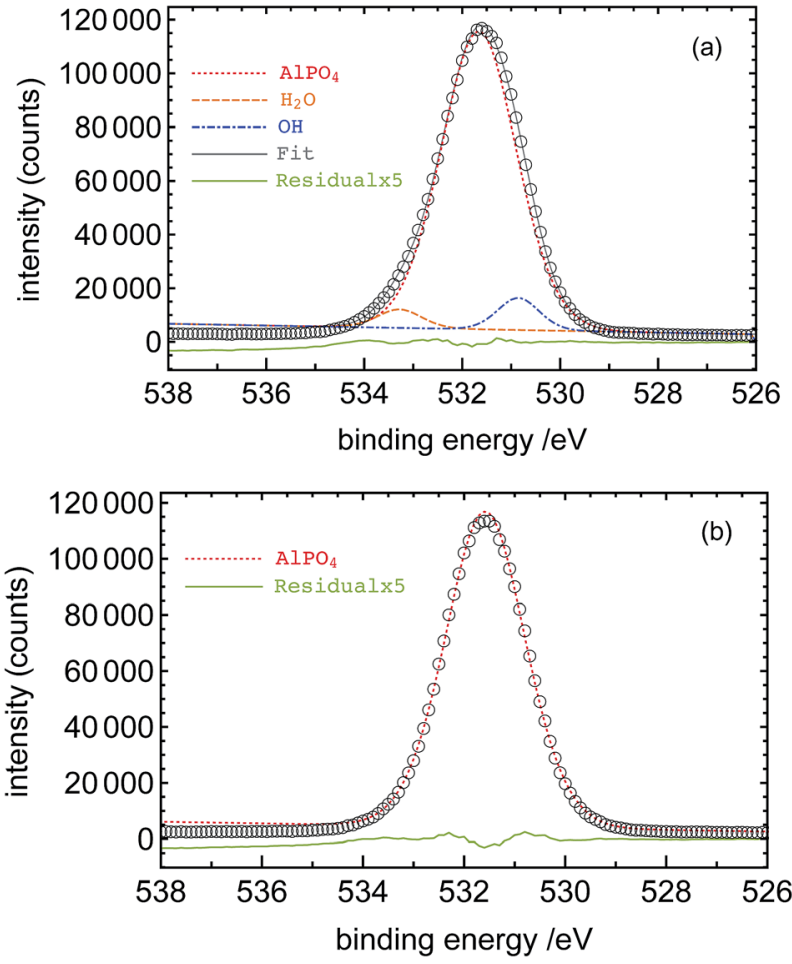

Fig. 3 XPS spectra of the $O$ 1s peak of LiAIPO films as a function of annealing temperature: (a) $275^{\circ} \mathrm{C}$ and (b) $400{ }^{\circ} \mathrm{C}$. Experimental data (open circles), $\mathrm{AlPO}_{4}$ fit (red), $\mathrm{H}_{2} \mathrm{O}$ fit (orange), $\mathrm{OH}$ fit (blue), and residual fit (green).

corresponding to $\mathrm{AlPO}_{4}(531.7 \mathrm{eV}), \mathrm{H}_{2} \mathrm{O}(533.3 \mathrm{eV})$ and $\mathrm{OH}^{-}(530.9$ $\mathrm{eV}$ ), whereas at $400{ }^{\circ} \mathrm{C}$, the $\mathrm{O} 1 \mathrm{~s}$ signal is entirely attributed to $\mathrm{AlPO}_{4}$. The relatively minor contribution of $\mathrm{H}_{2} \mathrm{O}$ and $\mathrm{OH}^{-}$to the $\mathrm{O}$ 1s XPS signal, the constancy of the relative oxygen content by XPS between the $275^{\circ} \mathrm{C}$ and $400{ }^{\circ} \mathrm{C}$ samples, and the absence of water vibrations in the IR suggest that the film is nearly completely dehydrated at $275^{\circ} \mathrm{C}$.

XPS data indicates the ratio of nitrogen to aluminium in films annealed at $275{ }^{\circ} \mathrm{C}$ is $1: 10$ suggesting most residual nitrogen has been eliminated by this temperature. Furthermore, the $\mathrm{N}$ 1s signal was extremely weak suggesting minimal nitrogen content. Annealing at $400{ }^{\circ} \mathrm{C}$ resulted in the continued reduction of the $\mathrm{N} 1 \mathrm{~s}$ peak supporting elimination of nitrate stretches as observed by FTIR. The single Li 1s peak located at $55 \mathrm{eV}$ is indicative of lithium in a phosphate environment and inconsistent with that of lithium oxide $(53 \mathrm{eV})$.

Scanning electron microscope (SEM) images shown in Fig. 4 demonstrate the high quality of the deposited films with respect to smoothness, density, and porosity. No apparent cracking or obvious film disruptions are observed despite the high volume of water loss required for film formation. We propose that the initial conversion of metal hydroxides in the precursor solution to metal oxide networks during film formation is a relatively forgiving transition that alleviates stress. Additionally, the ease with which decomposed counterions are expelled from the film prevents the high level of porosity observed in organic precursor systems. This is in stark contrast to that typically observed in more traditional sol-gel methods based on organic precursor

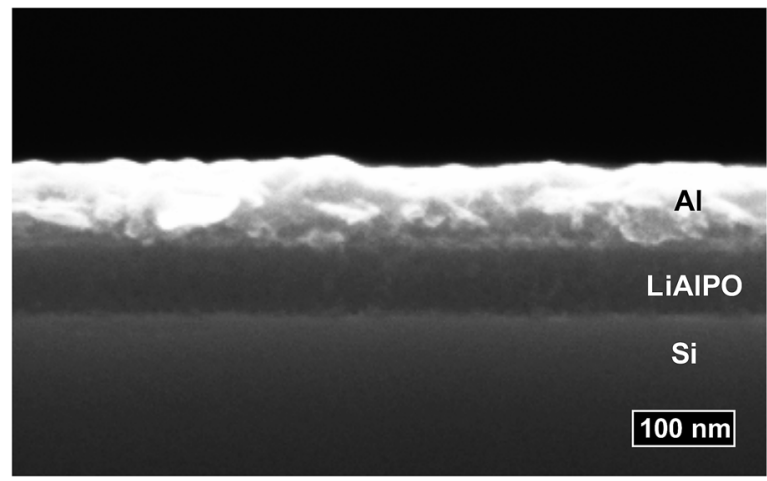

Fig. 4 Cross-sectional SEM image of LiAIPO film annealed at $275^{\circ} \mathrm{C}$ for one hour.

systems. The fact that only relatively small molecules, such as $\mathrm{H}_{2} \mathrm{O}, \mathrm{HNO}_{3}$ or $\mathrm{NO}_{2}$ from nitrate decomposition, need be expelled is believed to contribute to the formation of compact films with little porosity.

The thickness of films produced can be readily controlled by adjusting precursor solution concentration and spin speed. In this work, single layer films from $20 \mathrm{~nm}$ to $150 \mathrm{~nm}$ were fabricated from $0.1 \mathrm{M}$ to $0.8 \mathrm{M}$ precursor solutions, respectively (Fig. S2 $\dagger$ ). These results are consistent with other studies of Al$\mathrm{P}-\mathrm{O}$ films produced using PIC. ${ }^{28}$

Lithium ion conductivities of the LiAlPO films were determined using impedance spectroscopy. Fig. 5 shows the resulting dielectric functions measured at room temperature. The real part of the apparent conductivity, $\sigma_{\text {app }}^{\prime}$, as a function of frequency yields a small plateau region where the DC ionic conductivity was determined. As the $\mathrm{Al}$ and $\mathrm{Si}$ electrodes are blocking to lithium ions, polarization of ions at the electrodeelectrolyte interface is indicated by capacitive behaviour at low frequency. The plateau region observed at intermediate frequencies is attributed to the bulk resistance of the solid electrolyte film. The separation of capacitive ion polarization at low frequency from a potentially frequency dependent conductivity makes rigorous extraction of the DC conductivity

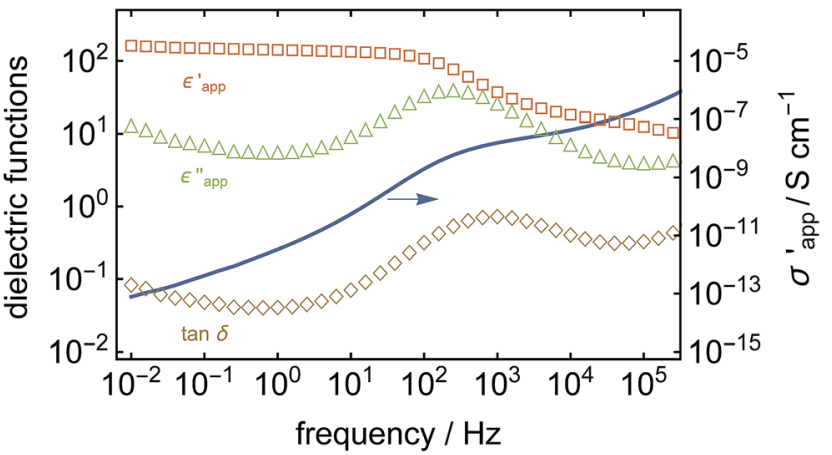

Fig. 5 Impedance data at $23^{\circ} \mathrm{C}$ of a $74 \mathrm{~nm}$ thick LiAlPO film annealed at $275^{\circ} \mathrm{C}$. The real part $\varepsilon^{\prime}$ app (orange squares) and imaginary part $\varepsilon^{\prime \prime}$ app (green triangles) of the apparent relative permittivity, the real part of apparent conductivity $\sigma_{\text {app }}^{\prime}$ (blue line, right ordinate), and the loss $\operatorname{tangent} \tan \delta$ (brown diamonds). 
challenging and model dependent. ${ }^{29}$ For consistency, we take the conductivity at the frequency corresponding to the peak in the dielectric loss as an estimate of the DC ionic conductivity, as has been done in other systems. ${ }^{30}$ The room temperature DC conductivity of films annealed at $275^{\circ} \mathrm{C}$ was calculated to be $\sigma_{\mathrm{DC}}$ $=2.6 \times 10^{-8} \mathrm{~S} \mathrm{~cm}^{-1}$ for $74 \mathrm{~nm}$ films. This conductivity is comparable to the literature value of $2.8 \times 10^{-8} \mathrm{~S} \mathrm{~cm}^{-1}$ for bulk glasses of nominally the same composition, but prepared using high temperature methods. ${ }^{26}$ While we recognize that the conductivity is below that of other solid electrolytes currently used in battery research, it should be noted that the level of conductivity was maintained with the use of a more environmentally sustainable approach. Furthermore, the method of synthesis provides ample opportunity to improve conductivity through chemical modification as discussed below. Activation energies were determined by plotting $\log \sigma_{\mathrm{DC}}$ versus $1 / T$ according to the Arrhenius equation: $\sigma=A \exp \left[-E_{\mathrm{a}} /(k T)\right]$ where $A$ is the pre-exponential factor, $E_{\mathrm{a}}$ is the activation energy, $k$ is the Boltzmann constant, and $T$ is temperature. The value of $E_{\mathrm{a}}$ extracted from the linear fit of the $\log \sigma_{\mathrm{DC}}$ versus $1 / T$ is $0.67 \mathrm{eV}$, consistent with that reported for bulk LiAlPO. ${ }^{26}$

The real part of the apparent permittivity ( $\left.\varepsilon_{\text {app }}^{\prime}\right)$ as a function of frequency and temperature is shown in Fig. 6. The low frequency side is assigned to the polarization of ions against the blocking electrodes, and yields a large value $\varepsilon_{\text {app }}^{\prime}=100$ for a $68 \mathrm{~nm}$ film. Consistent with this assignment is the fact that the low frequency $\varepsilon^{\prime}$ app is observed to depend on the thickness
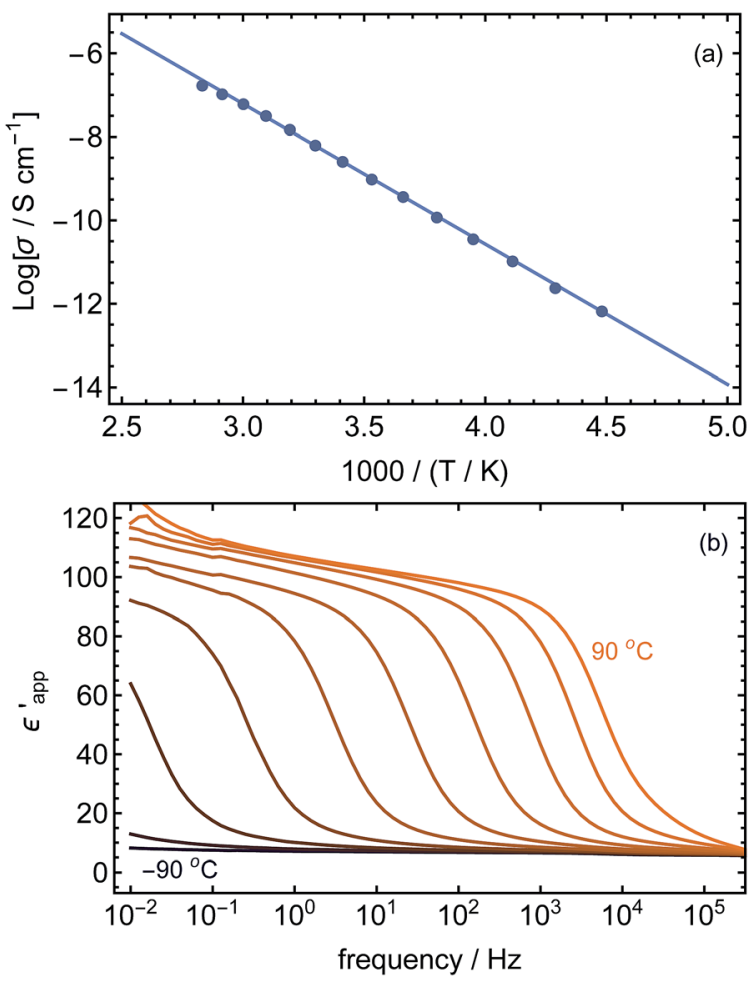

Fig. 6 (a) Arrhenius plot of the DC conductivity $\sigma_{\mathrm{DC}}$ value at the peak in the loss tangent $\tan \delta$ frequency from $74 \mathrm{~nm}$ thick LiAlPO film. (b) Frequency dependent $\varepsilon_{\text {app }}^{\prime}$ as a function of temperature over the range $-90^{\circ} \mathrm{C}$ to $90^{\circ} \mathrm{C}$ in $20^{\circ} \mathrm{C}$ increments for the same sample. of the film. This is because the characteristic length of the ionic double layer is the Debye length of the electrolyte, rather than the thickness of the film. The ionic polarization necessary to form an electrode double layer results in a constant contribution to the capacitance, regardless of film thickness, which manifests as a thickness dependent $\varepsilon^{\prime}$ app. The high frequency dielectric constant is near 6 , which is slightly above that of AlPO, and it is thickness independent. ${ }^{28}$ In addition to the longrange motion of lithium ions that contribute to ionic double layer formation at the electrodes, lithium displacements over shorter ranges contribute to the bulk dielectric constant at higher frequencies leading to an increased dielectric constant relative to AlPO.

The large double layer capacitance of thin-film ISEs has led to interest as gate dielectrics in field-effect transistors. ${ }^{\mathbf{9}, 31}$ Primarily, these studies have focused on monovalent cation incorporation into aluminium oxide materials resulting in sizeable capacitance and a subsequent reduction in operating voltages. ${ }^{9,31-33}$ Specifically, Liu et al. observed an increased capacitance in alkali metal ion incorporated alumina used as gate dielectrics for oxide field-effect transistors. The standard alumina films had a low frequency capacitance of $0.13 \mu \mathrm{F} \mathrm{cm}^{-2}$. Incorporation of lithium into the alumina increased that value to $1.8 \mu \mathrm{F} \mathrm{cm}^{-2}$. Our lithium incorporated alumina phosphate has a low frequency capacitance of $1.6 \mu \mathrm{F} \mathrm{cm} \mathrm{cm}^{-2}$, suggesting these films might be of interest for this application.

The ionic conductivity of the LiAlPO films is directly linked to annealing conditions. We postulate that the rapid dehydration associated with PIC prevents rigid organization within films resulting in non-bridging oxygen atoms with which Li ions are able to associate to give a non-random hopping mechanism of conduction. ${ }^{34,35}$ However, the actual annealing temperature is also important. Annealing at $400{ }^{\circ} \mathrm{C}$ resulted in a reduction in observed ionic conductivity $\left(\sigma=1.6 \times 10^{-10} \mathrm{~S} \mathrm{~cm}^{-1}\right)$. This result is expected when considering the spectroscopic data and the proposed mechanism of ion conduction. The O 1s XPS peak at elevated annealing conditions is entirely assigned to $\mathrm{AlPO}_{4}$ suggesting the elimination of non-bridging oxygen atoms necessary for lithium ion conduction. At these annealing conditions, the inorganic condensation is pushed near completion resulting in the formation of a stable $\mathrm{AlPO}_{4}$ framework. Mobile lithium ions lose association sites required for long-range motion and the resultant conductivity is significantly reduced.

\section{Conclusions}

We have reported a low energy approach to the synthesis of thin-film ISEs via aqueous solution deposition. LiAlPO thin films produced via prompt inorganic condensation demonstrate a room temperature conductivity of $2.6 \times 10^{-8} \mathrm{~S} \mathrm{~cm}^{-1}$ (thickness $=74 \mathrm{~nm}$ ) and activation energy of $0.67 \mathrm{eV}$. These values are consistent with lithium ion conduction observed in bulk LiAlPO samples but produced via energy intensive melt quenching techniques. Precise control over desired film thickness via precursor concentration was achieved with pinhole free films obtained over the $20 \mathrm{~nm}$ to $150 \mathrm{~nm}$ thickness range. 
The combination of solution deposition and low temperature processing is a unique approach to the synthesis of ISE thin films. Previously, synthesis routes to lithium alumino phosphates have been limited to melt quenching syntheses of bulk powders processed between $750{ }^{\circ} \mathrm{C}$ and $950{ }^{\circ} \mathrm{C} .{ }^{19,26,36}$ Solution based syntheses of other ISEs have required temperatures ranging from $650{ }^{\circ} \mathrm{C}$ to excess of $1000{ }^{\circ} \mathrm{C}^{37,38}$ We have successfully reduced processing conditions to $275{ }^{\circ} \mathrm{C}$ using an aqueous solution route that allows production of high quality thin-film ISEs. Reducing processing temperatures is a first step in extending the direct synthesis of ISE thin films to substrates beyond silicon and glass, such as those desired for flexible electronics. Because homogenous solution precursors are used, incorporation of additives or metal substitutions to increase film conductivity is readily achieved. ${ }^{26,39}$ This study serves as a first step towards future work that seeks to vary composition for new solution processed ISEs as a way to maximize their conductivity. Finally, PIC allows for the direct deposition of ISEs as smooth, dense thin films that are ideal for layered systems requiring high quality interfaces such as nanolaminates, batteries, and thin film transistors, without the use of vacuum deposition. ${ }^{17,31}$

\section{Acknowledgements}

This material is based upon work supported by the National Science Foundation under Grant No. CHE-1102637.

\section{Notes and references}

1 J. C. Bachman, S. Muy, A. Grimaud, H.-H. Chang, N. Pour, S. F. Lux, O. Paschos, F. Maglia, S. Lupart, P. Lamp,

L. Giordano and Y. Shao-Horn, Chem. Rev., 2016, 116, 140-162.

2 P. Knauth, Solid State Ionics, 2009, 180, 911-916.

3 E. Quartarone and P. Mustarelli, Chem. Soc. Rev., 2011, 40, 2525.

4 J. Zosel, F. De Blauwe and U. Guth, Adv. Eng. Mater., 2001, 3, 797-801.

5 J. A. Kilner and M. Burriel, Annu. Rev. Mater. Res., 2014, 44, 365-393.

6 J. B. Goodenough and P. Singh, J. Electrochem. Soc., 2015, 162, A2387-A2392.

7 C. Zhong, Y. Deng, W. Hu, J. Qiao, L. Zhang and J. Zhang, Chem. Soc. Rev., 2015, 44, 7484-7539.

8 J. Jensen and F. C. Krebs, Adv. Mater., 2014, 26, 7231-7234.

9 B. N. Pal, B. M. Dhar, K. C. See and H. E. Katz, Nat. Mater., 2009, 8, 898-903.

10 J. B. Goodenough and Y. Kim, Chem. Mater., 2010, 22, 587603.

11 K. Takada, Acta Mater., 2013, 61, 759-770.

12 D. A. Keszler, J. T. Anderson and S. T. Meyers, in Solution Processing of Inorganic Materials, John Wiley \& Sons, Inc., 2008, pp. 109-129.

13 M. Alemayehu, J. E. Davis, M. Jackson, B. Lessig, L. Smith, J. D. Sumega, C. Knutson, M. Beekman, D. C. Johnson and D. A. Keszler, Solid State Sci., 2011, 13, 2037-2040.

14 S. T. Meyers, J. T. Anderson, D. Hong, C. M. Hung, J. F. Wager and D. A. Keszler, Chem. Mater., 2007, 19, 4023-4029.
15 K. Jiang, A. Zakutayev, J. Stowers, M. D. Anderson, J. Tate, D. H. McIntyre, D. C. Johnson and D. A. Keszler, Solid State Sci., 2009, 11, 1692-1699.

16 K. Jiang, J. T. Anderson, K. Hoshino, D. Li, J. F. Wager and D. A. Keszler, Chem. Mater., 2011, 23, 945-952.

17 K. Jiang, S. T. Meyers, M. D. Anderson, D. C. Johnson and D. A. Keszler, Chem. Mater., 2013, 25, 210-214.

18 S. T. Meyers, J. T. Anderson, C. M. Hung, J. Thompson, J. F. Wager and D. A. Keszler, J. Am. Chem. Soc., 2008, 130, 17603-17609.

19 M. V. N. V. D. Sharma, A. V. Sarma and R. Balaji Rao, J. Mater. Sci., 2009, 44, 5557-5562.

20 Y. Wang, Z. Liu, X. Zhu, Y. Tang and F. Huang, J. Power Sources, 2013, 224, 225-229.

21 M. S. Bhuiyan and M. Paranthaman, Supercond. Sci. Technol., 2006, 19, R1-R21.

22 Y. Aoki, T. Kunitake and A. Nakao, Chem. Mater., 2005, 17, 450-458.

23 M. Bockmeyer and P. Löbmann, Thin Solid Films, 2007, 515, 5212-5219.

24 E. J. van den Ham, N. Peys, C. De Dobbelaere, J. D'Haen, F. Mattelaer, C. Detavernier, P. H. L. Notten, A. Hardy and M. K. Van Bael, J. Sol-Gel Sci. Technol., 2014, 73, 536-543.

25 S. Yuvaraj, L. Fan-Yuan, C. Tsong-Huei and Y. Chuin-Tih, J. Phys. Chem. B, 2003, 107, 1044-1047.

26 C. V. Koti Reddy, R. Balaji Rao, K. Chandra Mouli, D. V. Rama Koti Reddy and M. V. Ramana Reddy, J. Mater. Sci., 2012, 47, 6254-6262.

27 W. Xu, H. Wang, F. Xie, J. Chen, H. Cao and J.-B. Xu, ACS Appl. Mater. Interfaces, 2015, 7, 5803-5810.

28 K. M. Norelli, P. N. Plassmeyer, K. N. Woods, B. A. Glassy, C. C. Knutson, M. Beekman and C. J. Page, Solid State Sci., 2016, 55, 8-12.

29 J. R. Macdonald, Phys. Rev. B: Condens. Matter Mater. Phys., 2005, 71, 184307.

30 F. Lin, Y. Wang and M. Lonergan, J. Appl. Phys., 2008, 104, 103517.

31 Y. Liu, P. Guan, B. Zhang, M. L. Falk and H. E. Katz, Chem. Mater., 2013, 25, 3788-3796.

32 J. Sun, C. Qian, W. Huang, J. Yang and Y. Gao, Phys. Chem. Chem. Phys., 2014, 16, 7455.

33 Y. Liu, A. K. Diallo and H. E. Katz, Appl. Phys. Lett., 2015, 106, 112906.

34 B. Wang, J. Liu, Q. Sun, R. Li, T.-K. Sham and X. Sun, Nanotechnology, 2015, 25, 1-8.

35 I. A. Sokolov, Y. P. Tarlakov, N. Y. Ustinov and A. A. Pronkin, Russ. J. Appl. Chem., 2005, 78, 741-746.

36 I. Jlassi, H. Elhouichet and M. Ferid, Phys. E, 2016, 81, 219225.

37 S. Duluard, A. Paillassa, L. Puech, P. Vinatier, V. Turq, P. Rozier, P. Lenormand, P.-L. Taberna, P. Simon and F. Ansart, J. Eur. Ceram. Soc., 2013, 33, 1145-1153.

38 B. Key, D. J. Schroeder, B. J. Ingram and J. T. Vaughey, Chem. Mater., 2012, 24, 287-293.

39 J. K. Feng, L. Lu and M. O. Lai, J. Alloys Compd., 2010, 501, 255-258. 